\title{
¿QUIÉN SE ROBÓ MI PROPIEDAD? EL TRATAMIENTO DE LOS RECURSOS NATURALES MINEROS A LA LUZ DE LAS TEORÍAS DE DOMINIO PÚBLICO Y SU APLICACIÓN EN EL PERÚ WHO STOLE MY PROPERTY? THE TREATMENT OF NATURAL MINING RESOURCES SEEN THROUGH THE THEORIES OF PUBLIC DOMAIN AND THEIR APPLICATION IN PERU
}

\author{
Milagros Mutsios Ramsay* \\ Rodrigo, Elías \& Medrano
}

\begin{abstract}
The way in which the private property regime is structured often delimits the way in which a society is organized. In the mining aspect, ownership of natural resources is usually the main reason for the proper functioning of the system or endless disputes between native communities and state agencies.

In this sense, in order to better understand how the pubic domain system is structured on natural resources in our country, Milagros Mutsios explains in this article the four main public domain theories of natural resources and delves into the various concepts that influence the adoption or operation of each of these.
\end{abstract}

KEY WORDS: Public domain; natural resources; property; deposit; extraction.
La forma en como está estructurado el régimen de la propiedad privada muchas veces delimita la manera en que está organizada una sociedad. En el aspecto minero, la propiedad de los recursos naturales es generalmente la razón principal del buen funcionamiento del sistema o de las disputas interminables entre comunidades nativas y organismos del Estado.

En este sentido, para poder entender de mejor manera cómo está estructurado el sistema de dominio público sobre los recursos naturales en nuestro país, Milagros Mutsios explica en este artículo las cuatro principales teorías de dominio público de los recursos naturales y ahonda acerca de los diversos conceptos que influyen en la adopción o funcionamiento de cada uno de estos.

Palabras Clave: Dominio público; recursos naturales; propiedad; yacimiento; extracción.

\footnotetext{
Abogada. Asociada del Área de Recursos Naturales y Medio Ambiente del Estudio Rodrigo, Elías \& Medrano. Adjunta de los cursos de Derecho Minero y Electricidad, Derecho Societario y Seminario de Derecho Mercantil de la Pontificia Universidad Católica del Perú. Contacto: mmutsios@estudiorodrigo.com.
} 
Al estudiar el tratamiento de los recursos naturales mineros en el Perú, la literatura jurídica normalmente nos muestra un análisis desde un estudio de la propiedad. Es decir, se pregunta ¿quién es el titular de los recursos naturales?, buscando encontrar una respuesta en la asignación de estos a partir de la propiedad sobre el suelo o el subsuelo.

Sin embargo, difícilmente se analiza el tratamiento de los recursos naturales minerales desde las teorías del dominio público, aun cuando estos son entendidos, en la mayoría de regulaciones -incluyendo la peruana-, como bienes de dominio público frente a los cuales el Estado asume facultades para su otorgamiento a través de un título habilitante (por ejemplo: concesión de exploración o explotación ${ }^{1}$, contrato de concesión ${ }^{2}$, mining lease ${ }^{3}$ ). A partir de lo anterior, la necesidad de cambiar la orientación de la pregunta respecto de la "titularidad" de los recursos naturales minerales atendiendo a la propia regulación vigente es imperativa.

En un intento por solucionar esta problemática, a continuación se analizarán brevemente las teorías de dominio público que explican el tratamiento de los recursos naturales, con la finalidad de construir el concepto de dominio público aplicable a los recursos naturales mineros en el marco de la regulación peruana vigente.

\section{TEORÍAS DE DOMINIO PÚBLICO}

Tomando en cuenta los conceptos de dominio público desarrollados en la doctrina administrativa, específicamente por Proudhon, Hauriou, LópezRamón, Villar Palasí, Vergara, entre otros, es posible diferenciar cuatro sistemas que determinan el origen del dominio público minero: (i) teoría patrimonialista, (ii) teoría del dominio eminente, (iii) teoría dominialista o de dominio público, y (iv) teoría funcionalista (o de la publicatio minera) ${ }^{4}$, cuyos alcances procederemos a desarrollar.

\section{A. Teoría patrimonialista}

La teoría patrimonialista define el concepto de dominio público a partir del derecho de propiedad que tiene el Estado sobre los bienes. Uno de los primeros y principales exponentes de esta teoría es Hauriou. Este autor considera que los bienes de dominio público son perfectamente apropiables y, por lo tanto, "es perfectamente concebible la vigencia de derechos de propiedad" (Martínez Vázquez, 2000, p. 265).

Al sustentar esta teoría en un derecho de propiedad, el primer cuestionamiento a sus postulados fue la inaplicación de las características del derecho de propiedad civil a la propiedad administrativa. Al respecto, Parejo, analizando los estipulados de Hauriou, sostiene que el derecho sobre el dominio público es un derecho de propiedad (específicamente privada) independientemente de si los postulados del derecho civil no le son aplicables en su integridad pues la propiedad civil es solo un tipo que propiedad que no agota la institución (1983, pp. 2395-2396).

Lo desarrollado por Hauriou posteriormente fue seguido por Mayer quien, entre otros postulados, afirma que "[e]l dominio público es una propiedad del Estado que depende del derecho público" (Parejo, 1983, p. 2398). De acuerdo con la opinión de Parejo, "[e]l objetivo de Mayer era, pues, la sustitución del dualismo de la teoría dominante alemana por una institución unitaria denominada "propiedad pública", en la que se funda el poder patrimonial y el poder público o policía sobre la cosa o el bien público. El fundamento lo suministra la afirmación de que todo lo perteneciente a la

En Chile, para llevar a cabo la minería, es necesario contar con una concesión de explotación y exploración, sin que tales se sujeten a la obligación de hacer trabajos o invertir para mantenerlas (Varela y Silva, 2013, p. 73).

2 En Colombia, el Estado controla los derechos mineros, y dado que es "propietario" del subsuelo, la adquisición de derechos mineros requiere la ejecución de un contrato de concesión con la correspondiente autoridad minera (Mancero, 2014, p. 59).

3 En Canadá, los derechos mineros se clasifican en licencias de exploración y mining lease. Este último otorga a su titular el derecho a desarrollar actividades de explotación y procesamiento (beneficio) a una escala comercial (Richer, Massé y Honeyman, 2014, p. 67).

4 Estas no son las únicas teorías aplicables para entender la naturaleza jurídica de los recursos naturales. En el derecho alemán, por ejemplo, se ha desarrollado la teoría de la valorización. Esta teoría parte de considerar que la características impuestas a los bienes públicos por la teoría "clásica" que se sustenta en la propiedad (sean algunas de estas, inalienabilidad, imprescriptibilidad e in-embargabilidad) resulta un obstáculo para su valorización; "y, por eso es necesario encontrar fórmulas de dinamización que, sin perjudicar la afectación de dichos bienes (aquí radica la clave), consignan una gestión más eficaz y rentable para las arcas públicas" (Moreu, 2014, p. 143). Adicionalmente, Moreu señala que: "La doctrina alemana se esfuerza desde hace pocos años en elaborar una "teoría general de la adjudicación administrativa" a partir de ejemplos [...] como [...] los recursos naturales [...].Estos autores proponen una nueva modalidad de actividad denominada de "adjudicación de derechos limitados en número", partiendo de la idea de que todos los procedimientos en los que la Administración pública tiene que resolver problemas de escasez comparten unas características comunes. El régimen de las cosas públicas encajaría también en esta modalidad de adjudicación, en tanto que estamos ante recursos escasos y limitados en número cuyo reparto controla la Administración (2014, p. 144). 
«administración pública» no cae bajo el Derecho civil, pues incumbe al Derecho administrativo" (1983, p. 2398) [El énfasis es nuestro].

La tesis de que el dominio público parte del otorgamiento de un derecho de propiedad al Estado sobre los bienes públicos en base a las reglas del derecho administrativo se contrapone con lo afirmado por López-Ramón quien, al analizar la naturaleza de los bienes públicos, establece que es civil porque "el régimen general de los bienes públicos tiene su acomodo natural en el Código Civil, puesto que tal régimen implica una excepción al principio general de que los bienes son las cosas susceptibles de ser apropiadas" (2015, p. 218) [EI énfasis es nuestro].

Así, cabe concluir que si bien la tesis patrimonialista otorga un derecho de propiedad sobre los bienes de dominio público, no es pacífico en su análisis al determinar bajo qué rama del Derecho debe ser estudiada la extensión de este derecho de propiedad. Ya en 1983, Parejo establece como un cuestionamiento principal el determinar si la naturaleza de dominio público es un problema de Derecho Administrativo o no (1983, p. 2393).

Diversas críticas se han establecido a esta teoría patrimonialista. Así, una crítica a la teoría patrimonialista desarrollada por López-Ramón, la encontramos en el análisis del concepto de dominio público efectuado por Moreu quien afirma que "López Ramón considera que el dominio público es un derecho real de propiedad, igual que la propiedad civil y por eso el Código Civil es su lugar natural de regulación" (2014, p. 140) [El énfasis es nuestro]. Sin embargo, este mismo autor, en el intento por desarrollar la "escala de publicidad de las cosas" establece como nexo causal la potestad y no la propiedad estatal, es decir, "el elemento definidor del concepto de dominio público no es la propiedad (o no solo la propiedad), sino el conjunto de las potestades o facultades exorbitantes de la Administraciones públicas que garantizan la afectación de dichos bienes" (Moreu, 2014, p. 141).

Adicionalmente, "[...] una de las críticas a los defensores de la teoría patrimonialista es la constatación de que el supuesto dominio estatal sobre los recursos naturales se limita al otorgamiento de concesiones a particulares para su aprovechamiento" (Huapaya, 2015, p. 409). Es decir, no cabe afirmar que la teoría de dominio público se sostenga de un derecho de propiedad pues

[...] el Estado no se comporta como propietario respecto de los recursos naturales, sino que únicamente se comporta como [su] administrador [...], con ciertos poderes para disciplinar su uso y protección, pero sin tener facultades de libre disposición o para gravar tales bienes, los cuales en realidad son inalienables e imprescriptibles, y además, el régimen de su utilización repudia al derecho privado, sino que se rige por legislación administrativa (Huapaya, 2015, p. 409).

A partir de lo anterior, la principal crítica a la teoría patrimonialista es que el Estado no cumple las "funciones típicas" de quien ejecuta un derecho de propiedad. Por el contrario, utiliza la figura de dominio público como medio para el otorgamiento de títulos administrativos de intervención. En ese sentido, nos encontraríamos frente a un supuesto en el que lo relevante es estudiar la función que ejerce el Estado respecto de los bienes públicos siendo trascendental delimitar sus funciones administrativas y no su presunto "derecho de propiedad" sobre los bienes de dominio público.

Con arreglo a lo anterior, lo importante a rescatar en base a esta teoría es que el dominio público es entendido como un derecho de propiedad sobre los bienes catalogados como tales. Sobre la base de la definición sustentada en el derecho de propiedad es que, en la doctrina, se cuestionó si esta teoría debía ser abordada desde el Derecho Civil o el Derecho Administrativo. Sin perjuicio de las diferencias, las críticas a esta teoría oscilan sobre la efectividad en el accionar del Estado respecto de esta presunta propiedad. Así, en el sector minero, cabe cuestionar cómo el hecho de que únicamente se otorguen concesiones respecto de bienes de dominio público (concesión minera recursos naturales minerales en su fuente) refiere a una inexistencia de este derecho; y mas bien nos posiciona en un escenario donde el Estado se comporta como un administrador respecto de los bienes públicos y no como su propietario.

\section{B. Teoría del dominio eminente}

En contraste con la teoría patrimonialista del dominio público, la teoría del dominio eminente parte de entender que el Estado ejerce una facultad "eminente", es decir, un derecho de soberanía sobre los bienes públicos. Al respecto, Vergara define al dominio eminente como "[...] aquella posibilidad que tiene el soberano ( $y$, por tanto, el Estado) de disponer de los bienes de los súbditos con base en un supuesto derecho de propiedad del Estado sobre todo el territorio (2014, pp. 637-638) [El énfasis es nuestro].

Esta posibilidad de disponer fue traducida por Proudhon como facultades de guardia y custodia que ejerce el Estado sobre los bienes de dominio público en el marco de su derecho de soberanía. 
De Guerrero, al analizar los postulados de Proudhon, afirma que este autor "distingue entre dominio público y dominio privado del Estado. Según su teoría, el Estado tiene un verdadero derecho de propiedad sobre su dominio privado, pero sobre el dominio público ejerce exclusivamente facultades de guardia y custodia. De esta manera, la relación existente entre el Estado y los bienes de dominio público se sustenta en un derecho de soberanía, pero no de propiedad" (2015, p. 49) [EI énfasis es nuestro]. Es decir, en base a esta teoría, el Estado es soberano en el aprovechamiento de los bienes de dominio público, lo cual le permite ejercer facultades de control respecto de su uso.

El sustento del dominio público como un derecho de soberanía ha llevado a autores a interpretar que no nos encontraríamos en una relación dominical (o de dominio público) sino en una de desarrollo de potestades públicas. Ello en tanto que "el Estado tiene poderes de guardia y vigilancia, pero que no mantiene una auténtica posición de titular dominial (propietario en el sentido atribuido por el Código Civil a esta posición subjetiva) respecto de dichos bienes. El dominio público sería, por tanto, una potestad pública y no una relación dominical" (Martínez Vázquez, 2000, p. 265) [El énfasis es nuestro].

En España, Colmeiro, siguiendo la teoría de Proudhon, diferencia entre bienes de dominio público y bienes de dominio del Estado. Los bienes de dominio público son aquellos que "pertenecen a todos los omes comunalmente, de tal manera que también pueden usar de ellos los que son de otra tierra extraña [...]" (De Guerrero, 2015, p. 50). Por otro lado, a los bienes de dominio del Estado, pertenecen aquellos que son propiedad de la Nación, "[s]e trata de bienes administrados por el Estado quien, en el ejercicio de sus funciones, puede adquirirlos, conservarlos, aprovecharlos y enajenarlos según las necesidades del servicio o los intereses sociales. Dentro del Dominio del Estado se incluyen [...] las minas [...]" (De Guerrero citando a Colmeiro, 2015, p. 50) [El énfasis es nuestro].

A partir de lo anterior, se concluye que, en efecto, el Estado no ejerce un derecho de propiedad sobre los bienes de dominio público pues estos bienes son de todos; mientras que, sobre los bienes de dominio del Estado, ejerce un mayor control sobre su administración orientada al servicio o los intereses sociales. En esta última categoría es que, para el autor citado, se encontrarían las minas.

La tesis de Proudhon fue aceptada hasta que Hauriou desarrolló la teoría patrimonialista fundamentada en la sección anterior. Al respecto, Parejo afirma que considerando al derecho de propiedad como concepto ordenador del dominio público,
Proudhon lleva "a sus últimas consecuencias el malentendido en que dicha interpretación descansa, formulando y estableciendo la distinción entre dominio público y dominio privado del Estado, con negación de todo derecho de propiedad sobre la primera categoría y reconocimiento respecto de ella al Estado únicamente de poderes de guarda y vigilancia (de policía)" (1983, p. 2394). En efecto, este autor no concuerda con la teoría de Proudhon y establece que Hauriou -con acierto- supera su tesis.

Sin perjuicio de esta discrepancia, es posible interpretar que esta teoría es aplicable al sistema jurídico peruano parcialmente, el cual, a diferencia de la tesis de Colmeiro quien interpreta a Proudhon, entiende a las minas como bienes de dominio público y no de dominio privado del Estado. En efecto, autores como Rodrigo han afirmado que

[...] en el Perú, el concepto de dominio eminente responde a la idea del dominio del Estado sobre ciertos bienes, sin ligarlo a la idea de un derecho de propiedad estatal sobre aquellos, sino como una facultad perteneciente al Estado como soberano. En un contexto en el que todos los peruanos, como dueños de los recursos naturales, no puede ponerse de acuerdo para decidir qué es lo que quieren hacer con los recursos naturales, la soberanía del Estado asume ese rol" (Castañeda y Flores, 2007, p. 217) [El énfasis es nuestro].

Al respecto, Pulgar Vidal ha afirmado que, en el Perú se ha regulado el acceso a los recursos naturales con base en un sistema dominial donde el dominio de los recursos naturales permanece en el Estado bajo la forma de "dominio eminencial". Es a partir de ello que el Estado tiene la facultad de otorgar derechos a los particulares sobre los recursos naturales (2011, pp. 21-22). Importa precisar que, en el marco de esta definición, el autor citado indica que el Estado debería mejorar, precisar y reforzar su rol de "administrador" de los recursos naturales para procurar su aprovechamiento sostenible, recomendando que se especifiquen las condiciones sociales y ambientales que deben cumplir los administrados que busquen aprovechar los recursos, bajo el riesgo de perder la titularidad respecto de estos (2011, p. 37).

Evidentemente la opinión mencionada no atiende a un sector extractivo específico. Sin embargo, no compartimos que tal recomendación se aplique al sector minero pues resultaría altamente discrecional que se cuestione la revocatoria de un derecho minero concesionado (dígase, concesión minera) por incumplir condiciones socio-ambientales cuando estas no son requisitos para su otorgamiento, sino que se analizan en el devenir del proyecto minero como "compromisos sociales y ambientales". 
En efecto, para obtener una concesión minera, por ejemplo, no se analizan los compromisos ambientales o sociales; por el contrario, tales compromisos forman parte del instrumento de gestión ambiental aplicable ${ }^{5}$ y su incumplimiento, si bien genera la imposición de sanciones (pecuniarias y no pecuniarias), no supone una revocatoria del derecho minero, ni del ambiental.

Finalmente, autores como Hernández, al analizar la naturaleza de los recursos naturales como patrimonio de la Nación peruana, ha afirmado que

Los defensores de esta teoría indican que debido al dominio eminente en su aceptación de soberanía interna, el Estado puede reglamentar el aprovechamiento de los recursos naturales en beneficio de toda la colectividad. Consecuentemente, la afirmación parecería dar a entender, que el Estado puede en el momento que lo estime conveniente, según el mejor interés de la colectividad, modificar el acto mediante el cual concedió el aprovechamiento del recurso natural a un particular. Esto no es verdad (y sus defensores bien lo saben), por la soberanía interna se ejerce con limitaciones establecidas en el ordenamiento constitucional; así en el caso de la Constitución Peruana, se establecen garantías y seguridades (estabilidades) (2010) [El énfasis es nuestro].

De lo anterior se concluye que la teoría del dominio eminente supone que el Estado ejerce la "soberanía interna" sobre los recursos naturales. De esta manera, tiene las facultades necesarias (legislativas, jurisdiccionales, expropiatorias e impositivas) para regular el manejo de los recursos naturales. Para Hernández, lo anterior no supone que el Estado tenga un derecho de propiedad sobre los recursos naturales, como se ha citado, a pesar de que la finalidad de esta teoría sí es otorgarle este derecho. Considerando lo anterior, nos encontramos frente a una teoría cuyo "contenido [...] y denominación aparentan otorgar importantes derechos y facultades al Estado, cuando en el fondo no aporta nada" (Hernández, 2010) [El énfasis es nuestro].
Por lo tanto, es cierto que, bajo esta teoría, el Estado puede reglamentar el otorgamiento, explotación, uso y demás facultades respecto de los recursos naturales. Sin embargo, tal actuación se encuentra limitada en el propio ordenamiento jurídico, como lo veremos en la sección siguiente, al analizar la regulación sobre los recursos naturales, con énfasis en los minerales.

\section{Teoría dominialista o de dominio público}

La teoría dominialista parte de la distinción de los bienes entre aquellos de dominio público y dominio de un privado. Ello lo diferencia de la teoría patrimonialista, en la que autores como Colmeiro los diferenciaban entre bienes de dominio público y bienes de dominio (privado) del Estado.

Alcarraz, al analizar la distinción entre bienes de dominio público y privado en el derecho francés, afirma que esta "[...] se impuso durante el siglo XIX partiendo de la idea de que ciertos bienes públicos, por razón de su asignación al uso de todos o más ampliamente por su utilidad pública, debían gozar de una protección jurídica peculiar. Sobre este fundamento fue construida la teoría denominada de la "demanialidad pública" (2015, p. 30) [El énfasis es nuestro]. Es decir, el que un bien sea de dominio público dependerá de su utilidad pública. Efectivamente, el concepto de "utilidad pública" es variable en el tiempo. De allí que sea posible concluir que ciertos bienes que eran considerados como bienes de dominio público, dejen de serlo a consecuencia de esta variación.

Para determinar que un bien es de dominio público, Parejo afirma que existen dos caminos: (i) uno a través de la propia sujeción del bien a un uso o interés público, determinado por la colectividad; y (ii) una decisión de poder que parte del Estado en uso de sus facultades (1983, pp. 2419-2420).

En la doctrina peruana, autores como Huapaya (2015) y Martínez Vázquez (2000), así como el Tribunal Constitucional a nivel jurisprudencial ${ }^{6}$, permiten concluir que esta teoría parte de otorgar a

En atención a lo regulado en el Decreto Supremo 040-2014-EM que aprobó el Reglamento de Protección y Gestión Ambiental para las Actividades de Explotación, Beneficio, Labor General, Transporte y Almacenamiento Minero, los proyectos mineros que suponen la ejecución de actividades de explotación y beneficio deberán contar con un instrumento de Categoría III, es decir, un Estudio de Impacto Ambiental Detallado (artículo 25). Adicionalmente, el artículo 46 de la mencionada norma precisa los Planes que contienen los Estudios Ambientales, entre ellos, el Plan de Manejo Ambiental y el Plan de Gestión Social.

6 Sobre la jurisprudencia cabe atender a los pronunciamientos emitidos por el Tribunal Constitucional. Así, en el fundamento 29 del proceso acumulado Exp. 015-2001-Al/TC, Exp. 016-2001-AI/TC, Exp. 004-2002-Al/TC; así como, la sentencia emitida en el marco del Expediente 006-96-Al/TC, permiten diferencias los bienes privados de los bienes públicos del Estado, en base a las características de inalienabilidad e imprescriptibilidad, atendiendo a lo establecido en el artículo 73 de la Constitución Política del Perú. 
los bienes las características de inalienabilidad e imprescriptibilidad. Al respecto, es importante considerar que ya Hauriou otorgaba la característica de "inalienabilidad" a los bienes públicos como sustento para la teoría patrimonialista. De allí que sea posible concluir que estas características no sean excluyentes de la teoría del dominio público, pudiendo aplicarse de manera transversal.

Sobre la característica de inalienabilidad, Gueda afirma que esta se traduce en que "[...] estos bienes se encuentran excluidos del tráfico privado (son res extra commercium) y, consiguientemente, no pueden ser objeto de ningún acto de disposición o gravamen [...] uno de los principios inspiradores del régimen jurídico de los bienes de dominio público [...] una de las reglas fundamentales del dominio público [...] [e]sta supone que no es posible jurídicamente vender bienes demaniales ${ }^{7 "}$ (1999, p. 342). Es decir, esta característica excluye a los bienes de dominio público. Aplicando esta teoría a los recursos naturales mineros, es correcto afirmar que serán bienes públicos aquellos que se encuentren en el yacimiento minero, distinto del mineral el cual, una vez extraído; y por ende, retirado de su fuente, puede ser comercializado, dejando de ser entendido como un bien público.

Por otro lado, la característica de imprescriptibilidad supone que los bienes de dominio público no pueden ser objeto de prescripción adquisitiva de dominio (Huapaya, 2015, p. 411). Esta característica, como lo ha afirmado Ccopa, tiene como fundamento la figura jurídica de la usucapión, a través de la cual un modo de adquirir la propiedad es por la posesión legítima (2004, p. 40). De esta manera, un bien de dominio público no sale de la esfera estatal por el tiempo que un privado lo ha poseído, aun cuando tal posesión haya sido legítima.

A la fecha, en el Perú, es posible aplicar esta teoría a los recursos naturales minerales en parte. De la lectura del artículo II del Título Preliminar del Texto Único Ordenado de la Ley General de Minería, aprobado por Decreto Supremo 014-92-EM (en adelante, "TUO de la LGM"), "[t]odos los recursos minerales pertenecen al Estado, cuya propiedad es inalienable e imprescriptible" [El énfasis es nuestro]. En la definición normativa citada confluyen la teoría patrimonialista, en la medida que se determina que los recursos minerales pertenecen al Estado; y, la teoría dominialista, en tanto los recursos naturales mineros se categorizan como bienes inalienables e imprescriptibles.
Al respecto, resulta relevante indicar que en el derecho chileno, en el artículo 19 de la Constitución también confluyen las teorías patrimonialista y de dominio público, estableciendo que "[e]l Estado tiene el dominio absoluto, exclusivo, inalienable e imprescriptible de todas las minas". Sobre este artículo Vergara -autor quien ha analizado el régimen minero chileno y su implicancia en las teorías de dominio público-afirma que:

[...] si se observa bien la realidad de las cosas, "el Estado", como supuesto propietario de toda la riqueza mineral in rerum natura, no hace nada parecido a un propietario; lo único que realiza como tal, es legislar; y, luego otorgar concesiones a quien las solicite.[...] Entonces, que en un sistema de libertad económica como el que rige en nuestro país, que el texto constitucional llame "dominio" al papel regulador (legislador) que cumple el Poder Legislativo es nada más que para mantener la consigna; pero no es real. Es tan rara esa supuesta propiedad global sobre la riqueza minera que el propio Estado, cada vez que desea excepcionalmente explotar yacimientos minerales [...], debe obtener, como cualquier persona, una concesión" (2012) [El énfasis es nuestro].

A partir de lo citado, el autor acepta que la realidad de las cosas es que el Estado es propietario sobre bienes que son inalienables e imprescriptibles. Sin perjuicio de ello, cuestiona tal derecho de propiedad.

Por otro lado, encontramos que en la jurisprudencia nacional también se favorece la teoría del dominio público, en parte orientado a la teoría del dominio eminente. Por ejemplo, en el fundamento 28 de la Sentencia del Tribunal Constitucional 0482004-AI/TC, se indica que "los recursos naturales [...] reposan jurídicamente en el dominio del Estado. El Estado, como la expresión jurídico-política de la nación, es soberano en su aprovechamiento".

Con arreglo a lo anterior, Huapaya afirma que "los recursos naturales son parte del dominio público del Estado, entendiéndose que en virtud a ello, tales recursos son considerados como bienes o cosas públicas, sujetos a la soberanía del Estado en su administración y explotación" (201, p. 412). En ese sentido, en opinión de este autor, la tesis mayoritaria de la doctrina constitucional y sectorial peruana niega que los recursos naturales sean bienes de dominio público. Por el contrario, afirman que son

\footnotetext{
Precisamos que Vergara ha afirmado que el término "demanial" es errado, siendo únicamente bienes de dominio público. Ello aun cuando autores como García de Enterría o Villar Palasí han utilizado el calificativo "demanial" para referirse a lo mismo: bienes de dominio público (Vergara, 1989, p. 791).
} 
"patrimonio de la Nación". Como consecuencia, "el Estado tiene un poder de dominio eminente [...] Es decir, sin afirmar que el Estado es "propietario" de los recursos naturales, se afirma que tiene un poder de dominio eminente" (2015, p. 411). Sin embargo, en su opinión, la teoría más acorde con la regulación y el sistema del derecho administrativo es la teoría del dominio público.

Así, sobre esta teoría y su aplicación al régimen jurídico nacional ha afirmado lo siguiente:

Es la tesis que adoptamos en nuestro ordenamiento siendo coherentes con la sistemática del derecho administrativo y con el hecho de que no puede confundirse la soberanía estatal, con el hecho de que el ordenamiento constitucional brinda una especial protección a ciertos bienes susceptibles de aprovechamiento económico a favor de la colectividad, es decir, que el Estado protege y ordena el aprovechamiento de los recursos naturales, bajo la etiqueta y régimen administrativo del dominio público" (2015, p. 412).

En consecuencia, hemos establecido que la teoría del dominio público parte de una distinción respecto de los bienes que luego impacta en la actuación del Estado. Así, se ha afirmado que las características que determinan la naturaleza de un bien como público son la inalienabilidad e imprescriptibilidad. Preliminarmente, se ha introducido características similares encontradas en la legislación y jurisprudencia peruana, y cómo, si bien autores afirman que únicamente se debería considerar esta teoría para analizar la naturaleza jurídica del dominio público en el Perú, en nuestra opinión es posible encontrar pinceladas de esta teoría junto con la teoría patrimonialista y la del dominio eminente. Posteriormente, analizaremos a detalle esta conclusión preliminar al construir un concepto de dominio público aplicable a los recursos naturales mineros.

\section{Teoría funcionalista (o de la publicatio mi- nera)}

Esta teoría parte de la idea que el "dominio público" antes que representar la propiedad o soberanía del Estado sobre bienes que son catalogados como públicos por sus características; representa un soporte jurídico de potestades estatales. Ha sido desarrollada, entre otros autores, por Verga- ra, quien rechaza la teoría patrimonialista y considera que para entender la naturaleza jurídica del dominio público minero no se debe partir de entender quién tiene la titularidad de la cosa, sino su potestad.

A partir de esta idea, Vergara construye una concepción funcionalista del dominio público; es decir,

[...] que el "dominio público", antes que un conjunto de bienes, lo que representa es un soporte jurídico de potestades; es un título jurídico de intervención que lo que permite es que el Estado o Administración titular esté en posición jurídica hábil para disciplinar las conductas de quienes utilicen las cosas calificadas como generales. Sin embargo, las minas [...] merecen un tratamiento especial, [...] cabe consideraras como res nullius y no como patrimonio estatal (2015a, p. 295).

Sobre los recursos naturales, el autor afirma que "para regular los recursos naturales es innecesario declararlos previamente del dominio del Estado [...] lo que importa es regularlos para que estén disponibles, con justicia, igualdad, equidad y razonabilidad, a todos los potenciales usuarios y explotadores audaces y cuidadosos" (2015, p. 304).

Así, esta tendencia de desestatización de bienes públicos y recursos naturales, se extiende a los recursos naturales minerales respecto de los cuales "[e]l legislador simplemente los "regula", evitando así todo tipo de apropiación apriorística, ya particular, ya estatal" (Vergara, 2015a, p. 309). Por lo tanto, carece de relevancia determinar quién es su propietario sino que el Estado pueda, en atención a sus facultades, regular el uso y explotación de las minas. A partir de esta conclusión, no se requeriría, por ejemplo, quitarlos del tráfico común sino imponer cargas en su tráfico.

Recordemos que, otras teorías como la dominialista han determinado que los recursos de dominio público son inalienables, y por ende, están fuera del tráfico comercial libre. En contraposición a tal entendimiento, la teoría funcionalista propone mantenerlos dentro del comercio pero controlar tal actividad $^{8}$.

Por otro lado, la teoría funcionalista ha sido defendida por Moreu, quien al analizar el derecho

Estado es "propietario" de los recursos pero, el administrado no paga por concepto de regalía, distinto a lo que sucede bajo el sistema jurídico peruano. De allí que pueda sostener que las minas deben ser consideradas como "res nullius y no patrimonio estatal". Evidentemente, si tal sistema se incluyera en el peruano, sería necesario reformar la Constitución vigente, específicamente, el artículo 73 mediante el cual se otorga a los bienes públicos las características de inalienabilidad e imprescriptibilidad. Adicionalmente, no podría requerirse el pago de regalías al Estado por el aprovechamiento de los recursos naturales, específicamente, mineros. 
español establece que "la doctrina "propietarista" considera el dominio público como derecho de propiedad, mientras que los "funcionalistas" o críticos afirman que su verdadera naturaleza jurídica es la de ser un título causal de intervención, una potestad-función" (2014, p. 139) [El énfasis es nuestro].

Respecto del derecho español, Martínez Vázquez analiza la teoría acogida por la regulación española y afirma que la defensa de la naturaleza jurídica de bienes de dominio público que no tenga su fundamento en el derecho de propiedad ha sido excepcional a nivel doctrinario. Dentro de esa excepción se encuentran autores como Villar Palasí quien ha afirmado que "la naturaleza jurídica del dominio público debe explicarse desde la consideración del mismo como un "título causal de intervención" y, no en base a un derecho de propiedad" (2000, p. 268). Así, el dominio público, en lugar de permitir al Estado desplegar derechos de propiedad civil, le permite ejercer su función social, garantizando la calidad de vida de los ciudadanos. A partir de allí, puede además, ejercer también su función de control (de policía) ${ }^{9}$.

En esta línea, la tesis de Villar Palasí citada por Vergara supone que

el dominio público, antes que un conjunto de bienes, lo que representa es un soporte jurídico de potestades; un título jurídico de intervención que lo que permite es que la administración titular esté en posición jurídica hábil para disciplinar los conductos de quienes utilicen las cosas calificadas como públicas, ordenándolas de acuerdo con las exigencias de los intereses generales (1990, p. 148) [El énfasis es nuestro].

Es decir, el dominio público se entiende como una técnica de intervención en el sentido funcional. Así,

[...] si la administración tiene públicos hoy una serie de dominios, no lo hace con el viejo sentido regaliano de dejar las cosas así, incrementando el acervo del príncipe; antes bien, está interesada en otorgar concesiones al máximo, despojándose aparentemente del contenido útil de lo publificado. Esta aparente contradicción es la que desvela totalmente la función de la publicatio: construir sobre ella el título de intervención" (Villar Palasí citado por Vergara, 1990, p. 148) [El énfasis es nuestro].

A partir de lo anterior, la teoría funcionalista parte de cuestionar la necesidad de declarar a bienes como "de dominio público" para que el Estado tenga control sobre ellos. Se plantea tal declaración como innecesaria a la luz del desarrollo de las facultades de control del Estado. En consecuencia, sin quitar del tráfico comercial a los "bienes públicos" (dentro de los que confluyen los recursos naturales), se establece a la "concesión" como el título habilitante idóneo para su aprovechamiento eficiente, independientemente que en estricto nada se esté concesionando. Téngase en cuenta que, a partir de esta teoría, el fin del uso de un "bien de dominio público" supone al Estado poder ejecutar sus funciones sociales y al mismo tiempo de control para el beneficio de los ciudadanos; y no responde a la necesidad de obtener una "prestación" por el otorgamiento del bien en uso (dígase, pago de regalías).

Finalmente, como lo hemos adelantado, el tratamiento de los recursos naturales mineros se rige por una teoría de dominio eminente yuxtapuesta con una de dominio público. Por lo tanto, la teoría analizada en la presente sección no aplicaría a la regulación nacional vigente; sin embargo, su análisis es trascendental para realizar un análisis crítico sobre la necesidad y alcance de las potestades estatales frente a los bienes de dominio público, en este caso, los recursos naturales minerales.

\section{CONSTRUCCIÓN DEL CONCEPTO DE DOMI- NIO PÚBLICO APLICABLE A LOS RECURSOS NATURALES MINERALES}

Habiendo desarrollado las teorías en torno al dominio público de los recursos naturales, en esta sección procederemos a construir (o reconstruir) el concepto de dominio público respecto de los recursos naturales mineros. Esta construcción partirá del análisis de los elementos subjetivo, objetivo, teleológico y normativo.

\section{A. Elemento subjetivo}

Analizar el elemento subjetivo supone determinar quién tiene titularidad sobre los recursos naturales minerales.

\footnotetext{
Sobre la idea de título causal de intervención, Ruiz ha afirmado que "[...] el dominio público encuentra su anclaje en su consideración como título causal de intervención, que permite al Estado administrar su régimen jurídico amparándose en la función social que cumplen las potestades públicas encaminadas al mantenimiento de la integridad patrimonial" (2012). Adicionalmente, citando a Parejo, López-Ramón afirma que el dominio público sería un título causal de intervención en la medida que las cosas públicas (o en este caso, los bienes públicos) son tales porque permiten que el Estado a través de su uso, garantice la calidad de vida de los ciudadanos. Por ello, la Administración no se limita a ejercer un derecho de propiedad civil sobre estos, sino que ejerce sus potestades al servicio del interés general (2011, p. 22).
} 
A partir de la Constitución de 1920 -primera en analizar las reglas de pertenencia de los recursos naturales, en palabras de Rubio (1999, p. 329)- la "titularidad" de los recursos naturales era tratada en base a una teoría de dominio público patrimonialista. Se pensaba que el Estado tenía derechos de propiedad sobre los recursos naturales.

Posteriormente, y hasta la fecha, nuestra regulación permite encontrar matices de la teoría de dominio eminente mediante la cual (i) los recursos naturales son patrimonio de la Nación, y (ii) el Estado, en su representación, ostenta diversas facultades y derechos relacionados con el "otorgamiento" a los privados.

De esta conclusión es posible afirmar que las teorías que parten de definir la titularidad de los recursos naturales minerales a partir de conceptos de propiedad, tales como, el sistema de accesión, ocupación, res nullius; y libertad de minas, no resultan aplicables. Ello en la medida que, el sistema que regula el dominio de los recursos naturales es uno que enfatiza la posibilidad de otorgar facultades y derechos a los particulares, no su propiedad.

Por lo anterior, reiteramos que al analizar la titularidad sobre los recursos naturales (siendo estos aquellos en su "estado natural"), tales son patrimonio de la Nación y, el Estado ejerce la "soberanía interna" sobre estos. En consecuencia, tiene las facultades necesarias (legislativas, jurisdiccionales, expropiatorias e impositivas) con el fin de regular el manejo de los recursos naturales (en este caso recursos naturales minerales).

\section{B. Elemento objetivo}

Atendiendo a lo regulado en el artículo 66 de la Constitución Política del Perú vigente, la Ley Orgánica de Recursos Naturales, Ley 26821 (en adelante, "LORN") y el TUO de la LGM, se concluye que los recursos naturales en su fuente son dominio del Estado; mientras que los frutos (o productos) son bienes privados, "propiedad" de los titulares de los derechos concedidos sobre ellos ${ }^{10}$. En este contexto importa definir qué y cuáles son los recursos naturales minerales y los elementos que lo integran (por ejemplo, yacimiento minero y mina).

\section{Recursos Naturales Minerales}

A partir de la regulación nacional, la Constitución de 1993 no define lo que debe entenderse por "recursos naturales". Únicamente se menciona su clasificación en renovables y no renovables (artículo 66 antes citado). La distinción comunmente conocida sobre ambos tipos de recursos es la permanencia o agotamiento del recurso, siendo únicamente posible afirmar, para el caso de los minerales, que estos se agotan.

Considerando estos vagos alcances de lo que es un recurso natural, Lastres afirmó que la definición más próxima se encuentra en el Código Civil (1994, p. 137). Sin embargo, a la fecha, resulta incongruente remitirnos al Código Civil para analizar el concepto de "recursos naturales" aplicable al derecho minero.

Por otro lado, el artículo 3 de la LORN define a los recursos naturales de la manera siguiente:

Artículo 3.- Se consideran recursos naturales a todo componente de la naturaleza, susceptible de ser aprovechado por el ser humano para la satisfacción de sus necesidades y que tenga un valor actual o potencial en el mercado, tales como: [...] f. Los minerales; [El énfasis es nuestro].

De lo anterior, se desprende que la LORN identifica que los recursos naturales deberán significar una (i) satisfacción de necesidades; y (ii) tendrán un valor actual o potencial en el mercado ${ }^{11}$. Estas características tampoco son ilustrativas pues no nos permiten definir el límite técnico del concepto de "recurso natural". Nuevamente, no se atiende a la posibilidad de transformación del recurso natural, y si luego de tales acciones puede seguir catalogándose como tal y; por ende, ser un bien de dominio público.

Al recurrir a una definición que atienda a aspectos técnicos, el alcance realizado por García Montufar resulta esclarecedor. Este autor, al definir el término "mineral" ha señalado lo siguiente:

El término 'mineral' empleado en un sentido extensivo incluye cualquier sustancia inorgánica, que pueda extraerse de la tierra para ser aprovechada, en estado sólido como roca,

10 Téngase en cuenta el artículo 4 de la Ley Orgánica de Recursos Naturales, Ley 26821.

11 Al respecto, cabe indicar que el Tribunal Constitucional, en un intento por desarrollar una definición respecto de los recursos naturales ha seguido estas características. Así, en el fundamento 28 del Exp. 0048-2004-Al ha definido a los recursos naturales como "[...] el conjunto de elementos que brinda la naturaleza para satisfacer las necesidades humanas $[\ldots]$ que tiene alguna utilidad actual o potencias para el hombre". 
arcilla refractaria, metales y carbón o en estado fluido como aguas minerales, petróleo y gas [...] En la actualidad se denominan minerales a los componentes de las rocas y menas (o matriz = relleno metalífero de una veta, conjunto de minerales valiosos y estériles), que se distingue por su composición química y propiedades físicas. Desde el punto de vista genético, los minerales son combinaciones químicas naturales (raramente elementos nativos $=$ metales y algunas otras sustancias que se encuentran en sus menas exentas de toda combinación), productos naturales de los distintos procesos físico-químico que se operan en la corteza terrestre (comprendidos los productos de la actividad vital de los organismos). La mayoría abrumadora de estos productos se halla en forma de minerales en estado sólido [...]. Los minerales son la materia prima a extraer de los yacimientos o depósitos minerales" (1989, p. 10) [El énfasis es nuestro].

Es decir, un "mineral" en sentido técnico es cualquier sustancia inorgánica que puede extraerse de la tierra para ser aprovechada. Esta sustancia se genera por diversos procesos físico-químicos naturales en la corteza terrestre dando lugar a un "depósito minero".

Teniendo en cuenta lo anterior, el TUO de la LGM ha limitado la extensión de lo que técnicamente podría ser catalogado como un "mineral". Así, lo ha definido de la manera siguiente, "[...] comprende todo lo relativo al aprovechamiento de las sustancias minerales del suelo y del subsuelo del territorio nacional, así como del dominio marítimo. Se exceptúan del ámbito de aplicación de esta Ley, el petróleo e hidrocarburos análogos, los depósitos de guano, los recursos geotérmicos y las aguas minero-medicinales" (artículo 1 del Título Preliminar).

Como puede apreciarse, las sustancias minerales excluyen a algunos componentes también ubicados en la corteza terrestre, como por ejemplo, el petróleo. Ello no significa que técnicamente no nos encontremos frente a un mineral, pero legalmente, tal recurso natural no es regulado por las normas hasta ahora descritas ${ }^{12}$.

En consecuencia, de la regulación y doctrina analizada, cabe concluir que serán recursos naturales minerales aquellos recursos ubicados en el suelo y en el subsuelo, incluyendo el dominio marítimo, susceptibles de ser aprovechados por el titular de una concesión minera para satisfacer sus necesidades; siempre que estos tengan un valor actual o potencial en el mercado. Adicionalmente, se encuentran excluidos de esta definición los hidrocarburos, depósitos de guano, recursos geotérmicos y aguas minero-medicinales (por ejemplo, aguas termales).

Habiendo planteado una definición de recursos naturales minerales, procederemos a definir la clasificación de los minerales y los elementos que se desarrollan a partir de este concepto (por ejemplo, yacimiento minero y mina).

\section{Minerales metálicos y no metálicos}

Teniendo una definición de los recursos naturales minerales en atención a la definición del término "mineral" desarrollado por García Montufar (1989, p. 10) citada en la sección anterior se concluye que, un "mineral" en sentido técnico es cualquier sustancia inorgánica que puede extraerse de la tierra para ser aprovechada que se encuentra ubicada en un yacimiento o depósito mineral.

Posteriormente desarrollaremos el concepto de "yacimiento mineral", pero en esta sección importará determinar el alcance del término mineral. Al respecto, Basadre ha afirmado que:

Dentro del concepto "sustancia mineral" no debe encerrarse una acepción restrictiva. El concepto "sustancia mineral" comprende todas las sustancias metálicas, no metálicas, carboníferas y elementos radioactivos. La ley minera peruana excluye de su esfera al petróleo e hidrocarburos análogos, depósitos de guano y aguas minero-medicinales, las que están sometidas a regímenes jurídicos especiales (1969, p. 5) [El énfasis es nuestro].

Considerando lo anterior, la regulación minera (TUO de la LGM, principalmente) excluye de su ámbito de aplicación a los hidrocarburos, depósitos de guano, recursos geotérmicos y las aguas minero-medicinales (artículo I del Título Preliminar). Asimismo, el artículo 13 de la mencionada norma establece que "[I]as concesiones mineras que se otorguen a partir de 15 de diciembre de 1991, se clasificarán en metálicas y no metálicas, según la clase de sustancia, sin superposición ni prioridad entre ellas" [El énfasis es nuestro].

12 En efecto, los hidrocarburos poseen una regulación específica incluyendo, entre otras normas, (i) la Ley Orgánica que norma las actividades de Hidrocarburos en el territorio nacional, Ley 26221, (ii) el Texto Único Ordenado de la Ley Orgánica de Hidrocarburos, aprobado por el Decreto Supremo 042-2005-EM; (iii) Reglamento de las Actividades de Exploración y Explotación de Hidrocarburos aprobado mediante Decreto Supremo 032-2004-EM; entre otros. 
No todas las regulaciones mineras distinguen a los minerales en estas dos categorías. Por ejemplo, la regulación minera colombiana regula una distinción entre metales preciosos, metales no preciosos; sustancias minerales no metálicas; petróleo; piedras preciosas y semipreciosas (Aramburo, 1984, pp. 44-45). Por lo tanto, la clasificación de las sustancias minerales responde a un interés del Estado, más que una realidad científica, "lo que origina la necesidad de reunir preceptos legales especiales para la riqueza del subsuelo generándose principios jurídicos especiales y propios" (Basadre, 1969, p. 5).

Sobre las sustancias metálicas, Vergara ha afirmado que:

Entre los minerales metálicos el más importante por sus variados usos es el hierro, a partir del cual, aleado con otros metales o metaloides, se produce hierro fundido o acero. El cobre se encuentra en forma de sulfuros y óxidos [...] son también metálicos, el aluminio, que se obtienen de la bauxita; el níquel; el cromo; el manganeso; el molibdeno; el cobalto; y el uranio y el radio, de amplia utilización todos ellos. Los llamados metales preciosos oro y plata tiene una significación muy especial en el desarrollo de la economía, por su utilización como elementos monetarios y sus múltiples aplicaciones científicas y ornamentales (2013, pp. 48-49).

Adicionalmente, sobre estos minerales, Baldeón ha afirmado que "la doctrina informa que a medida que la ciencia descubre un nuevo mineral o nuevas cualidades o aplicaciones de los ya conocidos, el derecho positivo lo atesora e incorpora en el conjunto de las cosas susceptibles de apropiación, [...]" (2016, pp. 135-136).

De lo citado cabe concluir que, no existe una lista taxativa de minerales metálicos (o minerales "preciosos"). Por el contrario, dependerá de los avances tecnológicos el determinar otras sustancias que ostenten las características físico-químicas necesarias para ser catalogados como sustancias metálicas. Como consecuencia, la regulación minera debe atender a estos alcances científicos, en lugar de condicionar la innovación a los conceptos legales.
Por otro lado, sobre las sustancias no metálicas, el autor citado indica que "[s]on sustancias minerales que sin haberse previamente beneficiado a través de procesos químicos, como en el caso de los minerales metálicos, satisfacen necesidades al ser humano en la industria de la construcción (arena, piedras, arcillas, mármol, ónix) o la industria de los cosméticos (talco)" (2016, p. 136).

Es decir, los minerales no metálicos no necesitan los procesos de beneficio (atendiendo a la definición de esta actividad en el TUO LGM) para ser bienes que puedan satisfacer las necesidades del hombre. Ello no sucede con los minerales metálicos, los cuales necesitan del beneficio justamente para poder separar las sustancias no minerales (por ejemplo, roca) de la parte mineral ${ }^{13}$. Precisamos que, el que no requieran "beneficiarse", en los términos regulados en el TUO de la LGM no supone que no requieren de un procesamiento para aumentar el valor comercial ${ }^{14}$.

\section{Yacimiento minero y mina}

Como hemos indicado líneas arriba, los minerales se encuentran depositados en una "yacimiento minero". Así es como tal constituye un lugar en el que existen minerales por obra de la naturaleza (García Montufar y Franciskovic, 2001, p. 18).

Algunos autores como Baldeón (2016, p. 123) diferencian el concepto de "depósito minero" del de "yacimiento minero". Así, un "yacimiento minero" será un depósito minero económicamente rentable; mientras no sea rentable solo deberá ser considerado como un "deposito minero". En esta línea, Vergara también atribuye la connotación económica al concepto de "yacimiento minero" indicando que estos "constituyen concentraciones de metal cuya extracción es rentable; de lo que se deriva que tal definición es básicamente económica." (2013, p. 48).

Somos de la opinión que resulta innecesario desarrollar dos conceptos independientes a partir de la rentabilidad de un lugar que posee minerales en el subsuelo; más aun cuando tal rentabilidad depende de diversas razones como la tecnología para extraerlos, purificarlos, entre otros; en adición a las características naturales del área. De esta manera, descubrir un yacimiento no consti-

13 Téngase en cuenta que, el artículo 17 del TUO de la LGM, define a la actividad de beneficio como: "[...] el conjunto de procesos físicos, químicos o físico-químico que se realizan para extraer o concentrar las partes valiosas de un agregado de minerales o para purificar, fundir o refinar metales; [...]".

14 Un mayor de desarrollo sobre el procedimiento de beneficio vinculado con la naturaleza jurídica de la concesión de beneficio se investigo como parte de la tesis de licenciatura titulada "Sacando el beneficio a la actividad minera. La concesión de beneficio del Código de Minería de 1900 al Texto Único Ordenado de la Ley General de Minería” 
tuye una información suficiente que asegure la posibilidad de aprovecharlo en cantidades económicamente rentables. De allí que sea necesario determinar si los yacimientos contienen minerales en porciones suficientes para constituirse como "riqueza mineral".

Sobre lo anterior, García Montufar y Franciskovic han afirmado que

[p]ara la evaluación de un yacimiento, en términos generales, es preciso determinar la cantidad de mineral que contiene el yacimiento, la calidad del mineral que contiene el yacimiento, la calidad del mineral (ley del mineral), datos que deben relacionarse con el precio del mineral en el mercado industrial.

De otro lado, será necesario establecer el método de explotación que se aplicará y el costo de extracción. Igualmente el coste de tratamiento o purificación del mineral, el impacto ambiental y el coste de transporte (2001, pp. 18-19).

Adicionalmente, García Montufar ha desarrollado el concepto de "yacimiento minero" en relación con la concesión minera y la mina, afirmando que el TUO de la LGM ha concentrado la definición de yacimiento en la figura jurídica de concesión minera de explotación en la medida que (i) el yacimiento es objeto de la concesión; y (ii) los particulares adquieren el derecho de explotar un yacimiento mediante la concesión minera. En efecto, lo anterior no significa que una concesión necesariamente ocupa todo un yacimiento minero, pues dependerá del titular minero peticionar la extensión que considere conveniente ${ }^{15}(1965$, p. 11).

Por lo anterior, un yacimiento minero será aquel lugar que cuente con un depósito de minerales que despierten un interés económico en la extracción del recurso allí dispuesto por la acción de la naturaleza. Enfatizamos que la acción que limita al concepto de "mineral" es la extracción. Así, una vez extraído, deja de ser un bien de dominio público.

Importa tener presente que "yacimiento minero" no es sinónimo de "mina". Tomando en cuenta las acepciones propuestas en el Diccionario de la Real Academia Española, "mina" es entendida como “1. Criadero de minerales de útil explotación. 2. Excavación que se hace para extraer un mineral.
[...]". Pareciera que, el concepto "mina" incluye la etapa de "desarrollo" regulada en el TUO de la LGM. En efecto, de acuerdo con el artículo 8 del TUO de la LGM el "desarrollo" es la "operación que se realiza para hacer posible la explotación del mineral contenido en un yacimiento". Por lo tanto, el "desarrollo" es la "operación" que hace posible la "actividad" de explotación del mineral contenido en un yacimiento.

Sobre esta conclusión, García Montufar y Franciskovic han afirmado que "la actividad de desarrollo prepara el yacimiento para su explotación. [...] En otras palabras no existe un derecho minero o concesión de desarrollo por constituir atribución inherente a las actividades de exploración y explotación" (1999, pp. 22-23). En ese sentido, si como resultado de las actividades de exploración, se demuestra que existen minerales en cantidades económicamente solventes (por ejemplo, de un yacimiento minero) y se decide explotarlos, será necesario hacer el "desarrollo" necesario para poder extraer (explotar) el mineral, es decir, construir una "mina".

En base a lo anterior, atendiendo al elemento objetivo, el límite del concepto de recurso natural minero es hasta su explotación. Por lo tanto, la facultad del Estado para permitir el aprovechamiento de este bien de dominio público a través de una concesión (por ejemplo, una concesión minera) se limita hasta esta etapa. Las etapas posteriores que conforman el ciclo minero, dentro de ellas la actividad de beneficio, se ejecutan respecto de bienes privados; razón por la cual no requieren de una concesión.

\section{Elemento teleológico}

Habiendo definido la "titularidad" de los recursos naturales minerales y su extensión, importa desarrollar la finalidad a la cual están destinados; en relación con la naturaleza de la propia actividad minera.

El artículo 66 de la Constitución vigente regula que los recursos naturales son patrimonio de la Nación. Al respecto, Ochoa y Kresaljia han afirmado que existe una titularidad respecto de los recursos que refiere al dominio eminente de la Nación (2009, p. 416). Adicionalmente, Rubio ha afirmado que "Ios recursos naturales tienen que ser dispuestos con atención a los intereses de largo plazo de la

\footnotetext{
5 Téngase en cuenta que, de acuerdo con el artículo 11 del TUO LGM, "[...].Las concesiones se otorgarán en extensiones de 100 a 1,000 hectáreas, en cuadrículas o conjunto de cuadrículas colindantes al menos por un lado, salvo en el dominio marítimo, donde podrán otorgarse en cuadrículas de 100 a 10,000 hectáreas. El área de la concesión minera podrá ser fraccionada a cuadrículas no menores de 100 hectáreas. Para el efecto, será suficiente la solicitud que presente el titular de la concesión".
} 
misma Nación y no en función de criterios de corto plazo que puedan beneficiar a un determinado gobierno o grupo" (1999, p. 331) [El énfasis es nuestro]. En consecuencia, el aprovechamiento de los recursos naturales está orientado a satisfacer los intereses de la Nación. De allí que el Estado sea quien, en su nombre, ostente facultades para determinar su forma de aprovechamiento.

Al respecto, importa considerar que el Tribunal Constitucional en el fundamento 29 del Expediente 00048-2004-Al, ha determinado que el artículo 66 de la Constitución vigente permite concluir que los recursos naturales en su fuente son Patrimonio de la Nación; y como tales, su explotación, debe beneficiarla (tanto a las generaciones actuales como futuras).

Queda establecido que el Estado ostenta el dominio respecto de los recursos naturales minerales (metálicos y no metálicos) en su fuente debido a que estos son patrimonio de la Nación. En ese sentido, las reglas que se emitan para el ordenamiento de su aprovechamiento tienen como objetivo buscar una explotación sostenible que favorezca la inversión pero al mismo tiempo genere beneficios tanto para las generaciones presentes como futuras del Perú. La actividad de beneficio no se debería sujetar a tales reglas en la medida que no se ejecuta respecto de un bien de dominio público.

Sobre lo anterior, resaltamos que "[I]a industria minera es extractiva con caracteres de una industria manufacturera gracias a la acción humana en la extracción y transformación de los minerales que nos ofrecen la naturaleza que no son puros, sino que están compuestos a asociados con otras sustancias minerales." (Baldeón, 2016, p. 123). Por lo tanto, una vez que los recursos naturales minerales no se encuentran en su fuente, el Estado ya no ejerce facultades ordenadoras de un bien de dominio público, razón por la que no corresponde el otorgamiento de una concesión.

En efecto, como lo hemos afirmado líneas arriba, "aprovechar" los frutos que se obtienen de la explotación de los recursos naturales minerales no necesita del otorgamiento de una concesión, pues estos no se encuentran en su fuente.

Lo concluido, no significa que el Estado debe dejar intervenir en la actividad minera, siempre pensando en el bienestar de la Nación; sino que su presencia se debe orientar a la fiscalización (en materia laboral, ambiental o de seguridad minera) mas no al otorgamiento de concesiones, pues ya no nos encontramos en un escenario frente al cual el Estado ostente su "dominio eminente".

\section{CONCLUSIONES}

El análisis planteado permite demostrar que el paradigma en base al cual hemos venido analizando la naturaleza jurídica de los recursos naturales y con ello, los títulos habilitantes que permiten su aprovechamiento, no atiende a la realidad del tratamiento de los minerales como bienes de dominio público. En nuestra opinión, es a partir de las teorías de dominio público que resulta posible cuestionar si el Estado debe o no tener facultades vinculadas con el manejo de este recursos y los límites a su actuación.

Así, desde una toma de conocimiento de las distintas teorías de dominio público y la reconstrucción del concepto de dominio público se concluye que (i) los recursos naturales mineros en su fuente no son de propiedad del Estado ni bienes privados, (ii) que el Estado únicamente ejecuta sus facultades de regulación frente a aquellos recursos naturales en su fuente; y (iii) una vez que los recursos naturales han sido extraidos, tales se insertan en la trafico comercial libre (sin que ello deba requerir la aplicación de un sistema de concesiones). En consecuencia, nuestro sistema minero es uno de características dominiales hasta que el mineral es extraído de su fuente, luego de ello, nos encontraríamos frente a la ejecución de actividades (en principio) libres.

Estas conclusiones parten del propio análisis integral de la regulación aplicable al sector minero en el Perú junto con la doctrina aplicable. En consecuencia, no resulta necesario modificar la regulación minera a efectos de adoptar las conclusiones arribadas en el presente artículo, pero sí representan premisas que deberían guiar el análisis de los títulos habilitantes mineros y sus características, siendo estos la puesta en práctica de facultades estatales.

Efectivamente, la re-construcción del concepto de dominio público aplicable a los recursos naturales permite sentar las bases teorícas para cuestionar los títulos habilitantes regulados a la fecha para ejecutar un proyecto minero (dígase, una concesión). Solo a partir de este análisis resulta posible identificar la extensión de las facultades del Estado respecto de los recursos naturales mineros; $y$, en consecuencia, cuestionar si las características de los derechos mineros necesarios para ejecutar actividades mineras resultan necesarias, aplicables, o si, por el contrario, cabe representar algunos títulos habilitantes en base a la propia naturaleza del sistema dominial adoptado en el Perú.

Tal análisis escapa del presente artículo el cual, como se indicó en la introducción, tiene como 
objetivo repensar el tratamiento de los recursos naturales minerales. Sin embargo, plantea un cuestionamiento inicial que permitirá dar pie a un mayor análisis respecto de los títulos habilitantes $\operatorname{mineros}^{16}$.

\section{REFERENCIAS}

Alcarraz, H. (2015). El dominio público francés frente a la Modernidad. En: López-Ramón, F. y O. Vignolo Cueva (coords.). El Dominio Público en Europa y América Latina. Lima: Circulo de Derecho Administrativo, pp. 25-46. DOI: https://doi.org/10.17345/1696

Aramburo, J. L. (1984). Curso de Derecho Minero. Segunda Edición. Bogotá: Editorial Temis Librería.

Baldeon, J. F. (2016). Tratado de derecho Minero Peruano. Lima: Jurista Editores.

Basadre, J. (1969). Derecho Minero Peruano. Segunda Edición. Lima: Tipografía y Offset Peruana S.A.

Castañeda, M. y J. L. Flores. (2007). Entrevista a Luis Carlos Rodrigo Prado. Invirtiendo en Recursos Naturales. En: Derecho \& Sociedad 29. Lima, pp. 213-218.

Ccopa, S. (2004). El Dominio Público, su Desafectación. Tesis de maestría en Derecho con mención en Derecho Civil. Lima: Pontificia Universidad Católica del Perú, Escuela de Graduados.

De Guerrero, C. (2015). Bases Históricas y Constitucionales del Dominio Público en España. En: López-Ramón, F. y O. Vignolo Cueva (coords.). El Dominio Público en Europa y América Latina. Lima: Circulo de Derecho Administrativo, pp. 47-74. DOI: https://doi.org/10.17345/1696

García Montufar, G. (1989). Apuntes de Derecho Minero Común. Lima: Colegio de Abogados de Lima.

(1965). Derecho de minería. Curso Universitario. Primera Parte. Lima: Universidad Nacional Mayor de San Marcos.

García Montufar, G. y M. Franciskovic. (2001). Derecho Minero: Doctrina, Jurisprudencia y Legislación Actualizada. Segunda Edición. Lima: Gráfica Horizonte S.A.
(1999). Derecho Minero Común. Doctrina, Jurisprudencia y Legislación. Lima: Gráfica Horizonte S.A.

Guedea, M. (1999). Propiedades públicas y propiedades de interés público. En: Derecho Administrativo: Parte Especial. Madrid: Editorial Civitas, pp. 311-372.

Hernández, E. (2010). Los Recursos Naturales y el Patrimonio de la Nación. Blog Estado y Propiedad. Recuperado de: https://estadoypropiedad.blogspot.pe/2010/08/los-recursos-naturales-y-el-patrimonio.html. DOI: https://doi. org/10.26439/iusetpraxis2011.n042.1519

Huapaya, R. (2015). El Régimen Constitucional y legal de los recursos naturales en el Ordenamiento Jurídica Peruano (una visión desde el derecho administrativo de los bienes públicos). En: López-Ramón, F. y O. Vignolo Cueva (coords.). El Dominio Público en Europa y América Latina. Lima: Circulo de Derecho Administrativo, pp. 395-417. DOI: https://doi. org/10.17345/1696

López-Ramon, F. (2015). Los Bienes Públicos en la Codificación Civil Latinoamericana. En: LópezRamón, F. y O. Vignolo Cueva (coords.). El Dominio Público en Europa y América Latina. Lima: Circulo de Derecho Administrativo, pp. 217-237. DOI: https://doi.org/10.17345/1696

Mancero, G. (2014). Colombia. Mining in 28 jurisdictions worldwide. Londres: Law Business Research LTD, pp. 57-65.

Martinez Vázquez, F. (2000). ¿Qué es el dominio público?. THEMIS-Revista de Derecho 40, pp. 263-276.

Moreu, E. (2014). El debate actual sobre el concepto y naturaleza del dominio público. En: Revista de Derecho Administrativo Económico 19, pp. 133-154.

Ochoa, C. y B. Kresaljia. (2009). Derecho Constitucional Económico. Lima. Fondo Editorial de la Pontificia Universidad Católica.

Parejo, L. (1983). Dominio Público: un ensayo de reconstrucción de su teoría general. En: Revista de Administración Pública 100-102, pp. 2379- 2244.

16 Para un análisis sobre la naturaleza jurídica de la concesión de beneficio partiendo de los conceptos desarrollados sobre el dominio público, véase: tesis de licenciatura "Sacando el beneficio a la actividad minera. La concesión de beneficio del Código de Minería de 1900 al Texto Único Ordenado de la Ley General de Minería”, escrita por la autora de este artículo. 
Pulgar-Vidal, M. (2011). Promoviendo la Gobernanza en el Acceso y Aprovechamiento de los Recursos Naturales. Centrando el Debate Electoral 2011-2016. Lima: Sociedad Peruana de Derecho Nacional y Universidad San Martín de Porres. Recuperado de: http://www.actualidadambiental.pe/wpcontent/uploads/2011/05/ promoviendo_gobernanza_mpv.pdf

Richerd, E., Massé, D. y J. Honeyman (2014). Chapter 6. Canada. En: The Mining Law Review. Londres: Law Business Research LTD, pp. 65-75.

Rubio, M. (1999). Estudio de la Constitución Política de 1993. Tomo 3. Lima: Fondo Editorial de la Pontificia Universidad Católica del Perú.

Ruiz, M. A. (2012). La potestad de desahucio administrativo. Madrid: Instituto Nacional de Administración Pública.

Varela, F. y J. J. Silva (2013). Chapter 12. Chile. Barros Silva Varela \& Vigil Abogados Ltda. En: The International Comparative Legal Guide to: Mining Law 2014. Reino Unido: Global Legal Group LTD, pp. 73-77.

Vergara, A. (2015). Derecho de Bienes Públicos en Chile. Recuento Doctrinario y Actualidad Normativa. En: López-Ramón, F. y O. Vignolo Cueva (coords.). El Dominio Público en Europa y América Latina. Lima: Circulo de Derecho Administrativo, pp. 299-334. DOI: https://doi. org/10.17345/1696

Vergara, A. (2014). La Contemporánea Regulación de la Minería en Chile. Crítica a las Teorías Tradicionales del Dominio Estatal de las Minas. En:
Revista de Doctrina, Jurisprudencia, Legislación y Práctica 93, pp. 633-654.

(2013). Sistema de Derechos Mineros. Santiago de Chile: Thomson Reuters y Legal Publishing.

(2012). Para regular los recursos naturales es innecesario declararlos previamente del dominio del Estado. Diario El Mercurio. Chile: 28 de diciembre de 2012. Recuperado de: http://www.elmercurio.com/Legal/Noticias/ AnalisisJuridico/2012/12/28/Para-regular-losrecursos-naturales-es-innecesario-declararlospreviamente-del-dominio-del-Estado.aspx

(1990). Teoría del Dominio Público y Afectación Minera. Revista Chilena de Derecho 1(17), pp. 135-159. Santiago de Chile: Pontificia Universidad Católica de Chile.

Villar Palasí, J. (1950). Naturaleza y regulación de la concesión minera. En: Revista de administración pública 1, pp. 79-116.

\section{LEGISLACIÓN, JURISPRUDENCIA Y OTROS DOCU- MENTOS LEGALES}

Decreto Supremo 014-92-EM. Texto Único Ordenado de la Ley General de Minería. En: Diario El Peruano, 03 de junio de 1992.

Ley 26821. Ley Orgánica para el aprovechamiento sostenible de los recursos naturales. En: Diario El Peruano, 26 de junio de 1997.

Tribunal Constitucional del Perú. Sentencia recaída en el Expediente 00048-2004-AI/TC, 1 de abril de 2005. 